\title{
ACCESS TO CREDIT AND SUSTAINABILITY OF RURAL HOUSEHOLDS POVERTY STATUS: A CASE FROM CÔTE D'IVOIRE
}

\author{
Zrakpa Melaine Ouoya \\ Université Félix Houphouët Boigny Abidjan \\ ouoyamelaine@yahoo.fr
}

\begin{abstract}
Based on data from the Households Living Standard Survey (ENV2015), we analyze the impact of credit on poverty status stability (ex-post and ex-ante poverty) and then study the regional gaps between poverty and vulnerability to poverty in the rural environment in Côte d'Ivoire. We slightly modified the model of Chaudhuri et al. (2002) to estimate the vulnerability to poverty and consider the poverty index as our measure of poverty. We construct a latent variable that is equal to the square of the gap between poverty and vulnerability to poverty and then use a tobit model to estimate the influence of credit on that variable. Our results show that credit makes poverty status unstable by widening the gap between ex-post and ex-ante poverty (poverty and vulnerability to poverty). We also find that the regional distribution of poverty is different from that of vulnerability to poverty in the rural environment in Côte d'Ivoire.
\end{abstract}

\section{Keywords}

Credit; poverty; vulnerability; sustainability; rural households; Côte d'Ivoire

\section{JEL Classification}

R20; I32

\section{Introduction}

In the field of development studies, the emergence of the theme of the economic vulnerability of populations dates from the beginning of the 2000s. It followed the analyzes of poverty and joined the analysis of the consequences of natural, political disasters or other which plunges or keeps part of the population in poverty. The economy generally conceptualizes the vulnerability of populations as the result of an insufficient response to a risk which is here that of becoming poor.

Households face various risks and do not know if a future shock will hit them in the future. The occurrence of such a shock could modify the poverty status of the household by tilting it into poverty (if it was not already there) or simply by keeping it in poverty if it was already poor. Thus, the assessment of poverty at a given time is a static approach, not taking into account possible changes in the future.

When assessing vulnerability, we refer to the dynamic perspective. Vulnerability is explicitly prospective and tries to include the risks likely to push people into poverty in the future. Vulnerability research is closely linked to the study of shocks and the risks they generate (Wisner et al. 1994). Their purpose is to identify the systems, elements of a system or the population groups most exposed to the consequences of a major disturbance. These approaches have led to the identification of "vulnerable systems" or "vulnerable populations", in order, with a view to prevention, to implement actions making it possible to reduce the consequences of shocks on the elements thus targeted. This approach has been qualified as epidemiological management (Bidou et al., 2012). In Côte d'Ivoire, like many developing countries, the measurement of poverty has been the subject of particular attention by decision-makers and researchers. Several works 
carried out mainly by state institutions have made it possible to measure poverty with a view to designing a policy to combat poverty. The 2008 household living standards survey conducted by the National Statistics Institute (INS) found that almost half of the population, or $48.9 \%$ of the population, was poor. The daily individual consumption of this segment of the population was less than 661 FCFA (adjusted poverty line). In 2015 (ENV2015), this same study conducted by the INS found a reduction in poverty to $46.3 \%$ with a poverty line established at 737 FCFA per day. Ouoya (2019) estimates the vulnerability to poverty of rural households in Côte d'Ivoire and founds that in the analysis sample $25 \%$ of households are poor while $34 \%$ are vulnerable to poverty. The work of Ouoya (2019) also showed that the sector of activity of the head of household, his level of education and his access to credit are significant determinants of the vulnerability of rural households to poverty. In the wake of these previous works, this study is interested in the analysis of the stability of the poverty status over time in view of a better impact of poverty reduction policies. It's about explaining the gaps between poverty and vulnerability given access to credit. Several specific objectives are thus targeted, namely:

- measuring poverty and vulnerability to poverty in rural areas in Côte d'Ivoire;

- studying the influence of access to credit on the stability over time of the rural households poverty status;

- $\quad$ analyzing the interregional heterogeneity between poverty and vulnerability to poverty.

It is for us to test two research hypotheses namely:

H1: Access to credit makes poverty status more stable over time;

$\mathrm{H} 2$ : There is a concordance between the regional distributions of poverty and vulnerability to poverty within the rural environment in Côte d'Ivoire.

This research will be conducted according to the plan designated below: the first section will be devoted to methodology, that is to say to the presentation of the analysis model and data. The second section will present the results of our analysis and the resulting discussions when the last section concludes.

\section{Methodology}

The data used to carry out our various models and the models themselves will be presented in this section. The first subsection will present these data that comes from the household standard of living survey conducted by the National Institute of Statistics (INS). The second subsection will be devoted to the presentation of the research methodology.

\section{The data}

The data used for this study come from the 2015 Household Living Standards Survey (ENV2015). This survey was carried out by the National Institute of Statistics (INS) Côte d'Ivoire. Its main objective was to collect information to improve the planning and evaluation of economic and social policies in Côte d'Ivoire.

The universe of this survey is made up of all African households residing in Côte d'Ivoire. The sampling frame used was the General Census of Population and Housing (RGPH2014). The total sample size is 12,900 households for the 33 strata (31 regions plus the city of Abidjan and the Yamoussoukro Autonomous District). Thus, this size makes it possible to guarantee representativeness at the level of each stratum.

This study focuses only on households living in rural areas. The database used includes 2,998 observations. Descriptive statistics for this study sample are available at the outcome level of our analysis. After presenting our database, we reveal in the following subsection the analysis model. 


\section{Analysis models}

Two measures are useful for the conduct of this work: on the one hand, the incidence of poverty (number of individuals whose consumption is below the poverty line), on the other hand, the probability of falling into poverty (prediction of poverty status). We predict the status of poverty and therefore vulnerability to poverty from the model presented by Chaudhuri et al. (2002) that we modify to take into account our requirements. This model predicts the probability of a household falling into poverty according to its socio-economic characteristics. We are modifying this basic model to take into account household access to credit.

Here, predictions of vulnerability to poverty will make it possible to classify the population into three groups, namely the very vulnerable (individuals whose probability of falling into poverty is greater than $50 \%$ ), the vulnerable (those whose probability is between incidence of poverty and 50\%) and the non-vulnerable (those whose probability of becoming poor is lower than the incidence of poverty). At the end of this first estimate, two lines of research will be retained for the rest of the work, namely the analysis of regional correspondences between poverty and vulnerability and then, the study of the determinants of the gaps between poverty and vulnerability.

Vulnerability is a prospective concept, and we retain that vulnerability is the risk or probability that a household will become or remain poor in the near future given its characteristics. Such characteristics consider socio-economic indicators and we add household access to credit as an additional variable. A household is poor if its consumption per equivalent adult is below the poverty line. Households vulnerable to future poverty are those with low levels of expected consumption and / or are subject to high variability in their well-being. We model the expectation of the mean and the variance of future per capita consumption.

The conditional mean of the log of future consumption is assumed to be linear to access to credit and to household characteristics. The regression model is as follows :

$$
\operatorname{lnPCC}_{i t+1}=\alpha+\beta X_{i t}+\theta \operatorname{Cred}_{i t}+\varepsilon_{i t}
$$

Where $P C C_{i t}$ denotes consumption per adult equivalent of household $i$ at current time $t, X_{i t}$ is a vector of socioeconomic characteristics of household $i$ at present $t$. Cred $d_{i t}$ is a binary variable taking the value 1 if household $i$ had access to credit during the last twelve months preceding the household standard of living survey and 0 if not. Beyond socioeconomic characteristics, we believe that access to credit has an impact on both current consumption and future household consumption (Ouoya, 2019). We assume that the mean of the error terms is independent of the $X_{i}$ and of the variable Cred $_{i t}$ that is to say :

$E\left[\varepsilon_{i t+1} \mid \operatorname{Cred}_{i t}, X_{i t}\right]=0$.

Similarly to Chaudhuri et al. (2002), we assume that the conditional variance is linearly related to access to credit and to the socioeconomic characteristics of the household. Given that

$E\left[\left(\ln P C C_{i t+1}-E\left[\ln P C C_{i t+1} \mid \operatorname{Cred}_{i t}, X_{i t}\right]\right)^{2} \mid \operatorname{Cred}_{i t}, X_{i t}\right]=E\left[\varepsilon_{i t+1}^{2} \mid \operatorname{Cred}_{i t} X_{i t}\right]$, the model variance regression model is as follows:

$\left(\varepsilon_{i t+1}\right)^{2}=\hat{\alpha}+\hat{\beta} X_{i t}+\hat{\theta}$ Cred $_{i t}+u_{i t+1}$

This two-equation model is estimated sequentially using ordinary least squares (OLS). We estimate equation (1) and the parameters obtained are used to construct the residuals. The squares of the residual parameters are used in equation (2) to estimate the conditional variance of future consumption by individuals in the household.

Chaudhuri et al. (2002) use the socioeconomic characteristics of the household to predict the future poverty status of the household. Bah (2015) concludes in his work that this procedure proposed by these authors is weak in its ability to accurately predict future poverty status. According to this author, the introduction of current consumption as a predictor of future consumption makes it possible to circumvent this problem. For 
our part, we introduce access to credit as a predictor given the influence it could have on the current level of household consumption.

According to the work of Chaudhuri et al. (2002), we assume that future consumption is $\log$ normally distributed with a conditional mean and variance obtained through the two-step regression presented above. This makes it possible to estimate the vulnerability to household poverty conditional on access to credit and household characteristics through the following model:

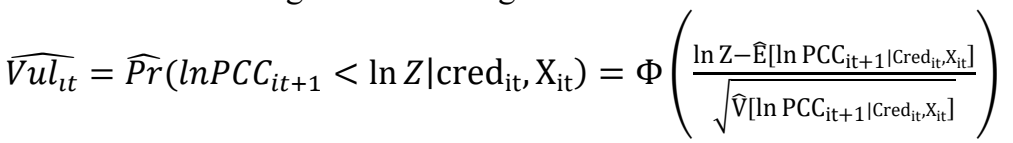

Where $Z$ is the poverty line.

Another way to estimate (3) is to directly estimate the probability of being poor in $t+$ 1 using a probit model and then hypothesizing that the conditional variance of future per capita consumption is constant across households. Bah (2015) finds that such a model is simpler to estimate and makes it possible, for example, to assess the importance to be given to the inter-temporal variance of consumption to depend on access to household characteristics.

For the evaluation of poverty, the indicator retained is the incidence of poverty or poverty ratio (P0) which is simply equal to the number of poor individuals compared to the total number of individuals. In 2015, any individual whose daily consumption is less than 737 FCFA or 269,075 FCFA per year is considered poor in Côte d'Ivoire.

Following the estimation of poverty and vulnerability to poverty, we design a latent variable equal to the square of the poverty / vulnerability to poverty gap. This latent variable is as follow :

$D P V_{h t}=\left(P 0_{h t}-V u l_{h t}\right)^{2}$

Where $D P V_{h t}$ denotes the square of the poverty / vulnerability to poverty gap of household $h$ at current time $t$. $\quad P 0_{h t}$ is a binary variable relating to the status of poverty; it takes the value 1 if the per capita consumption of household $h$ at current time $t$ is below the poverty line and 0 if not. $V u l_{h t}$ is the probability evaluated at current time $t$ for household $h$ to fall into poverty in the near future (Chaudhuri et al. 2002).

To estimate the determinants of the square of the poverty / vulnerability to poverty gap, we use a tobit model according to the following specification

$$
\begin{aligned}
& \widehat{D P V}_{h}=\alpha_{0}+\alpha_{1} C A_{h i}+\alpha_{2} F W_{h}+\alpha_{3} E L_{h i}+\alpha_{4} O D_{h}+\alpha_{4} A S_{h i}+\alpha_{5} \operatorname{Cred}_{h}+ \\
& \alpha_{6} H H S_{h}+\alpha_{7} M N_{h}+\mu_{h}
\end{aligned}
$$

Where $\widehat{D P V}_{h}$ represents the square of the gap between poverty and vulnerability to poverty at the household level $h . C A_{h i}, H H S_{h}$ are binary variables representing respectively the age categories $i$ of the head of household $h$, (less than 35 years; between 35 and 55 and more than 55) and the sex of the head of household $h$ ( 0 for women and 1 for men). The model dependent variable is used to assess the stability of the household's poverty status over time. When its value increases, the difference between poverty and vulnerability becomes greater and the present status of poverty cannot be relied on to conduct poverty reduction policies.

$F W_{h}$ is a binary variable taking the value 1 if the head of household $h$ has a full-time job and 0 if not. $E L_{h i}$ and $A S_{h i}$ are categorical variables indicating on the one hand the level of education $i$ of the head of household $h$ and the sector of activity $i$ of the head of household $\mathrm{h}$. Four levels of education are taken into account, namely: no level, primary level, secondary level and university level. Regarding the variable $A S_{h i}$, it also takes four values, namely 1 for agriculture, 2 for industry, 3 for trade and 4 for services. $O D_{h}$ and $\mathrm{Cred}_{h}$ respectively representing the fact that the household lodges in a dwelling of which it is owner then, the fact for the household having received a credit 
during the last twelve months preceding the ENV2015. The variable $M N_{h}$ refers to the number of males in the household $\mathrm{h}$. The dependent variable is as follows:

$$
\begin{aligned}
\widehat{D P V}_{h} & =\widehat{D P V}_{h}^{*} \text { si } \widehat{D P V}_{h}^{*}>0 \\
\widehat{D P V} & =0 \text { when } \widehat{D P V}_{h}^{*} \leq 0
\end{aligned}
$$

The coefficients $\alpha_{1}, \ldots, \alpha_{7}$ provide an appropriate adjustment to obtain consistent estimators revealing the effects of the changes on the dependent variable.

\section{Results and discussions}

This study, as mentioned above, assigns three specific objectives, namely, to measure poverty and vulnerability to poverty, to identify the determinants of the differences and then analyze the possible regional concordances between these two quantities. To do this, the global values obtained between these two variables should be presented in a crosstab. Table 1 below presents this information.

Table 1: Poverty crossing/vulnerability to poverty

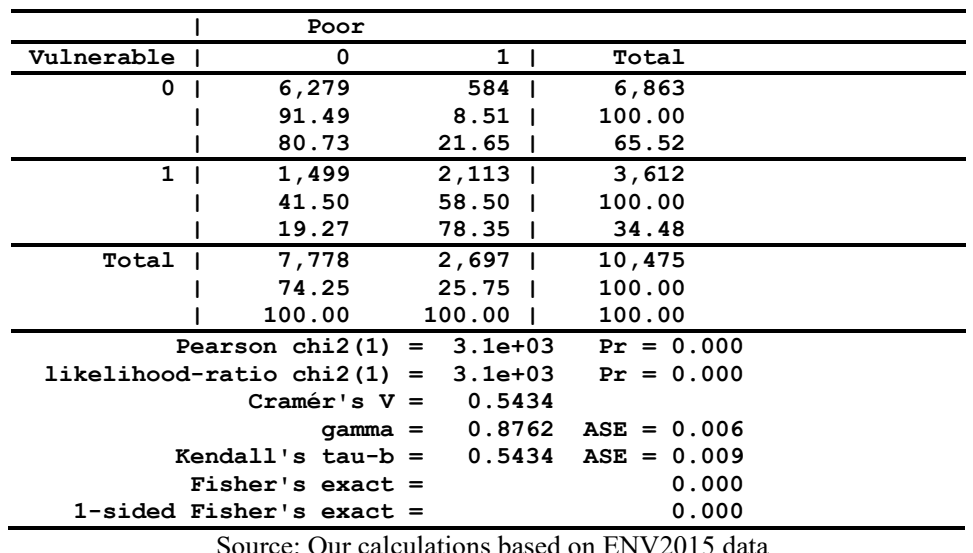

The usefulness of this table above resides in the fact that it shows us the global values of the variables which were used to evaluate the dependent variable of our final model. Apart from this fact, the results presented there have already been mentioned in the work of Ouoya (2019) which highlighted, like many works, that the vulnerable population is more important than the population poor in rural areas in Côte d'Ivoire. In general, there is a significant difference between poverty and vulnerability. A healthy appreciation of the gaps between poverty and vulnerability would be an asset for effective poverty reduction policies. By knowing the factors that can influence the stability of the poverty status over time, decision-makers will be able to conduct policies to fight poverty in an informed manner. And it is for this reason that we are directing this research towards identifying the determinants of the poverty / vulnerability to poverty gaps. The variable of interest is access to credit, but several control variables were introduced into the model. The descriptive statistics of the tobit model enabling this analysis to be made are presented in Table 2. 
Table 2 Descriptives statistics of tobit model

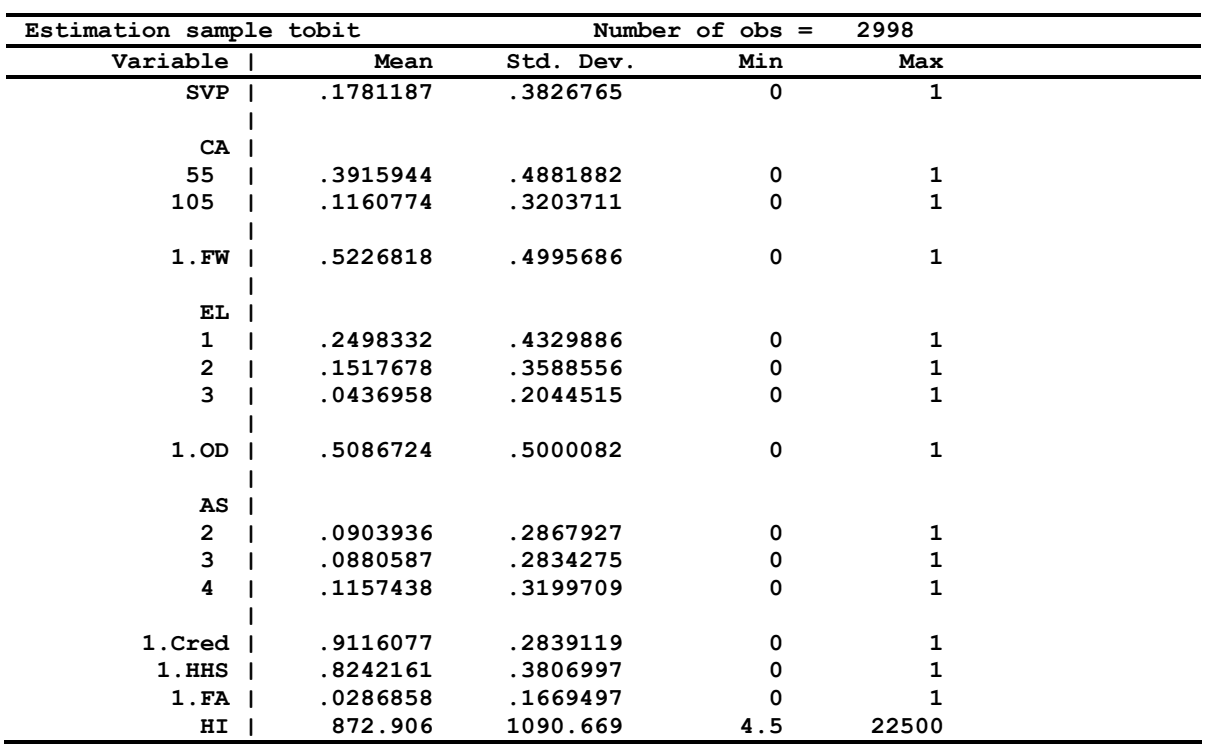

Source: Our calculations based on ENV2015 data

The breakdown by age group shows that the majority of rural household heads are young. Heads of households under the age of 35 occupy $50 \%$ of the workforce in the analysis sample. Likewise, the heads of households in the rural environment in Côte d'Ivoire are mostly without education with more than half of the sample size. Agriculture is the main source of income for rural households in Côte d'Ivoire. Three quarters of the heads of rural households exercise their main activity there.

In addition, it should be noted that rural credit is widely available since almost 90 percent of the workforce had access to credit during the last twelve months preceding ENV 2015. This is linked to the fact that the informal market is the main source of credit provision in the Ivorian rural environment (Ouoya, 2019). Finally, it should be noted that $82 \%$ of heads of rural households are men. Following this analysis of the descriptive statistics of the model, we present the results of the Tobit regressions in Table 3.

Table 3 Results of the tobit regression

\begin{tabular}{|c|c|c|c|c|c|c|c|}
\hline DVP & Coef. & St.Err & $\mathrm{t}$-value & $\mathrm{p}$-value & {$[95 \%$ Conf } & Interval] & Sig \\
\hline 35b.CA & 0.000 & & & & & & \\
\hline 55.CA & -0.775 & 0.086 & -9.02 & 0.000 & -0.944 & -0.607 & $* * *$ \\
\hline 105.CA & -0.759 & 0.130 & -5.83 & 0.000 & -1.014 & -0.504 & $* * *$ \\
\hline Ob.FW & 0.000 & 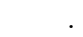 & 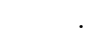 & & . & . & \\
\hline 1.FW & -0.168 & 0.071 & -2.38 & 0.017 & -0.307 & -0.030 & $* *$ \\
\hline 0b.EL & 0.000 & . & . & & . & . & \\
\hline 1.EL & -0.073 & 0.087 & -0.84 & 0.402 & -0.244 & 0.098 & \\
\hline 2.EL & -2.298 & 0.229 & -10.02 & 0.000 & -2.748 & -1.848 & $* * *$ \\
\hline 3.EL & -6.879 & . & . & . & . & . & \\
\hline 0b.OD & 0.000 & . & . & . & . & . & \\
\hline 1.OD & 1.153 & 0.095 & 12.19 & 0.000 & 0.967 & 1.338 & $* * *$ \\
\hline 1b.AS & 0.000 & . & . & . & . & . & \\
\hline 2.AS & -1.493 & 0.231 & -6.45 & 0.000 & -1.946 & -1.039 & $* * *$ \\
\hline 3.AS & 0.847 & 0.105 & 8.04 & 0.000 & 0.641 & 1.054 & $* * *$ \\
\hline 4.AS & 0.778 & 0.130 & 5.99 & 0.000 & 0.523 & 1.032 & $* * *$ \\
\hline
\end{tabular}




\begin{tabular}{|c|c|c|c|c|c|c|c|}
\hline Ob.Cred & 0.000 & . & & & . & & \\
\hline 1.Cred & 2.402 & 0.275 & 8.73 & 0.000 & 1.862 & 2.941 & *** \\
\hline Ob.HHS & 0.000 & 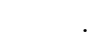 & & & 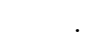 & & \\
\hline 1.HHS & -1.127 & 0.101 & -11.16 & 0.000 & -1.325 & -0.929 & $* * *$ \\
\hline Ob.SC & 0.000 & & & & & & \\
\hline 1.SC & -0.076 & 0.094 & -0.81 & 0.421 & -0.260 & 0.108 & \\
\hline $\mathrm{HI}$ & 0.000 & 0.000 & 1.29 & 0.195 & 0.000 & 0.000 & \\
\hline Constant & -2.508 & 0.289 & -8.66 & 0.000 & -3.076 & -1.941 & *** \\
\hline Constant & 1.136 & 0.042 & .b & .b & 1.054 & 1.219 & \\
\hline Mean dependent var & & 0.178 & \multicolumn{2}{|c|}{ SD dependent var } & & 0.383 & \\
\hline Pseudo r-squared & & 0.229 & \multicolumn{2}{|c|}{ Number of obs } & \multicolumn{2}{|r|}{2998.000} & \\
\hline Chi-square & & 853.543 & \multicolumn{2}{|c|}{ Prob $>$ chi2 } & \multicolumn{2}{|r|}{0.000} & \\
\hline Akaike crit. (AIC) & & 2902.93 & \multicolumn{2}{|c|}{ Bayesian crit. (BIC) } & \multicolumn{2}{|r|}{2993.021} & \\
\hline
\end{tabular}

The gap between poverty and vulnerability narrows when moving from a young head of household to an older head. Thus, heads of household aged between 35 and 55 and those over 55 have greater stability in terms of their poverty status compared to their counterparts under 35 . The results of the CA variable statistically significant at $1 \%$ reveal this state of affairs.

Heads of households with full-time employment (variable FW) have relatively stable poverty status compared to heads of households who do not. The negative coefficient of the FW variable is at the origin of this observation (significant at 5\%). The level of education has a significant impact on the statibility of the household's poverty status. Here, the higher the level of education, the narrower the gap between poverty and vulnerability. Thus, households whose head has a higher level of education have a more sustainable and more stable poverty status over time compared to households where the head has no education level. This fact is all the more worrying as more than half of the heads of rural households in Côte d'Ivoire have no level of education and the lack of stability of the poverty status is all the more a major obstacle to the sustainability of anti-poverty policies.

The household head's business sector also has a significant impact on the sustainability of the household's poverty status. Only the households whose head operates in the industry sector have a relative stability of their poverty status compared to households practicing in agriculture. On the other hand, there is an instability in the poverty status when one passes from a head of household working in agriculture to a head working in services or trade.

The variable of interest in our analysis is access to credit (Cred). It is significant at the 1 percent level. The result of the tobit regression shows that households with access to credit, compared to those without access to credit, record a larger gap between poverty and vulnerability (ex-ante poverty). Thus, the poverty status of these households is greatly modified by their access to credit. These results are in good agreement with the work of Ouoya (2019) which showed that access to credit reduces poverty but increases the vulnerability of rural households in Côte d'Ivoire. For Ouoya (2019), it is the nature of the credit, its source, the amount granted and the use of this credit that would explain the unsustainability of its effects on the short and long term poverty status of rural households in Côte d'Ivoire. Thus, it can be said that households that received credit have an unstable poverty status compared to households that did not receive credit in rural areas in Côte d'Ivoire.

Households headed by men compared to those headed by women have more stability in their poverty status. This result is significant at the 1 percent level. The availability of social capital by the household increases the stability of its poverty status. However, 
this latter result is not significant. Following this first discussion, we now focus on the analysis of regional poverty / vulnerability differences.

\section{Analysis of regional differences in poverty / vulnerability to poverty}

The regions with a poverty incidence above the national rate of $46.3 \%$ are as follows: autonomous district of Abidjan 52\%, Haut Sassandra region 47\%, Gbèkè region 51\%, Tonkpi region 55\%, Kabadougou region 69\%, N'zi region 49\%, Marahoué region 47\%, Worodougou region 50\%, Bafing region 49\%, Bagoué region 69\%, Folon region 59\%, Grands Ponts region 49\%, and the Tchologo region with 54\%. A total of 13 administrative districts have an incidence of poverty greater than the national level of poverty.

Table 4 Distribution of poverty and vulnerability to poverty in rural areas in

\section{Côte d'Ivoire}

\begin{tabular}{|c|c|c|c|c|c|c|}
\hline Region & $\begin{array}{l}\text { Mean } \\
\text { VUL }\end{array}$ & Mean P0 & VUL-P0 & $(\text { VUL-P0) })^{2}$ & $\begin{array}{c}(\text { VUL-P0) } \\
(\%)\end{array}$ & $\begin{array}{c}\text { Evolution } \\
\text { rate }(\%)\end{array}$ \\
\hline Abidjan District & 0,333 & 0,528 & $-0,195$ & 0,038 & 3,803 & $-36,932$ \\
\hline Haut-sassandra & 0,253 & 0,475 & $-0,222$ & 0,049 & 4,928 & $-46,737$ \\
\hline Poro & 0,460 & 0,444 & 0,016 & 0,000 & 0,026 & 3,604 \\
\hline Gbeke & 0,488 & 0,516 & $-0,028$ & 0,001 & 0,078 & $-5,426$ \\
\hline Indenie-djuablin & 0,218 & 0,413 & $-0,195$ & 0,038 & 3,803 & $-47,215$ \\
\hline Tonkpi & 0,498 & 0,556 & $-0,058$ & 0,003 & 0,336 & $-10,432$ \\
\hline Yamoussoukro District & 0,336 & 0,311 & 0,025 & 0,001 & 0,063 & 8,039 \\
\hline Gontougo & 0,011 & 0,407 & $-0,396$ & 0,157 & 15,682 & $-97,297$ \\
\hline San-pedro & 0,107 & 0,240 & $-0,133$ & 0,018 & 1,769 & $-55,417$ \\
\hline Kabadougou & 0,602 & 0,689 & $-0,087$ & 0,008 & 0,757 & $-12,627$ \\
\hline N'zi & 0,310 & 0,488 & $-0,178$ & 0,032 & 3,168 & $-36,475$ \\
\hline Marahoue & 0,326 & 0,467 & $-0,141$ & 0,020 & 1,988 & $-30,193$ \\
\hline Sud-comoe & 0,638 & 0,349 & 0,289 & 0,084 & 8,352 & 82,808 \\
\hline Worodougou & 0,741 & 0,495 & 0,246 & 0,061 & 6,052 & 49,697 \\
\hline Loh-djiboua & 0,494 & 0,435 & 0,059 & 0,003 & 0,348 & 13,563 \\
\hline Agneby-tiassa & 0,403 & 0,388 & 0,015 & 0,000 & 0,023 & 3,866 \\
\hline Goh & 0,401 & 0,440 & $-0,039$ & 0,002 & 0,152 & $-8,864$ \\
\hline Cavally & 0,244 & 0,263 & $-0,019$ & 0,000 & 0,036 & $-7,224$ \\
\hline Bafing & 0,229 & 0,495 & $-0,266$ & 0,071 & 7,076 & $-53,737$ \\
\hline Bagoue & 0,689 & 0,691 & $-0,002$ & 0,000 & 0,000 & $-0,289$ \\
\hline Belier & 0,085 & 0,412 & $-0,327$ & 0,107 & 10,693 & $-79,369$ \\
\hline Bere & 0,433 & 0,433 & 0,000 & 0,000 & 0,000 & 0,000 \\
\hline Bounkani & 0,219 & 0,442 & $-0,223$ & 0,050 & 4,973 & $-50,452$ \\
\hline Folon & 0,643 & 0,594 & 0,049 & 0,002 & 0,240 & 8,249 \\
\hline Gbokle & 0,022 & 0,328 & $-0,306$ & 0,094 & 9,364 & $-93,293$ \\
\hline
\end{tabular}




\begin{tabular}{l|c|c|c|c|c|c} 
Grands-ponts & 0,237 & 0,486 & $-0,249$ & 0,062 & 6,200 & $-51,235$ \\
\hline Guemon & 0,288 & 0,306 & $-0,018$ & 0,000 & 0,032 & $-5,882$ \\
\hline Hambol & 0,148 & 0,447 & $-0,299$ & 0,089 & 8,940 & $-66,890$ \\
\hline Iffou & 0,348 & 0,463 & $-0,115$ & 0,013 & 1,323 & $-24,838$ \\
\hline La me & 0,065 & 0,333 & $-0,268$ & 0,072 & 7,182 & $-80,480$ \\
\hline Nawa & 0,164 & 0,220 & $-0,056$ & 0,003 & 0,314 & $-25,455$ \\
\hline Tchologo & 0,438 & 0,536 & $-0,098$ & 0,010 & 0,960 & $-18,284$ \\
\hline Moronou & 0,151 & \multicolumn{2}{c|}{0,366} & $\begin{array}{c}-0,215 \\
0,046\end{array}$ & 4,623 & $-58,743$
\end{tabular}

The identification of regions with a ratio of vulnerable people higher than this same poverty index highlights the following regions: Gbèkè region 49\%, Tonkpi region $50 \%$, Kabadougou region $60 \%$, South Comoé region 64\%, Worodougou region 74\%, Lohdjiboua region 49\%, Bagoué region $69 \%$ and Folon region 64\%. Eight administrative districts were retained in this second selection. Of these eight administrative districts, six have been previously identified as part of the regions with high poverty rates. These are the regions of Gbèkè, Tonkpi, Kabadougou, Worodougou, Bagoué and Folon. Of the 33 constituencies identified, the vast majority, that is to say 25 , recorded a decrease between the incidence of poverty and the vulnerability to poverty ratio. This drop is very pronounced in regions such as Haut Sassandra, Indénié-djuablin, Gontougo, Sanpedro, N'zi, Marahoué, bafing, ram, Bounkani, Gboklè, Grands -bridges, the hambol, the Iffou, the Mé and the Moronou which recorded decreases of more than $30 \%$. Poverty should decrease in this districts over the next year if we stick to the results of our sample of 10,475 observations. The Goh, Cavally, Bagoué and Béré regions also recorded decreases, but these were very slight (less than 10\%). Other constituencies, on the other hand, recorded an increase between poverty and vulnerability to poverty. These are Poro, the Yamoussoukro autonomous district, Sud Comoé, Worodougou, Loh-djiboua, Agnéby-tiassa and Folon. The increase is more pronounced in the South Comoé, Worodougou where the increases between poverty and vulnerability to poverty are respectively $83 \%$ and $48 \%$. The rate of increase is between 5 and 20 percent at the level of the other regions having registered an increase between these two ratios. The statistically significant difference recorded in the incidence of poverty and the ratio of vulnerable households to poverty is reflected in the various administrative districts. Excluding the Poro region and the Béré, whose development rates are less than 5 percent, all the districts show differences between poverty and vulnerability with development rates ranging from around 10 for to over 80 percent. In such a context, it cannot be said that there is a correspondence between the spatial distribution of poverty and that of vulnerability to poverty in the rural area of Côte d'Ivoire.

\section{Conclusion}

At the end of our analysis, we found that the incidence of poverty in the analysis sample is 25.8 percent, while the ratio of vulnerable individuals to poverty is 34.5 percent. More than $3 / 4$ poor households are vulnerable to poverty, and one in five non poor households is found to be vulnerable to poverty. Our work, like Chaudhuri et al. (2002), concludes that the ratio of vulnerable to poverty is higher than the incidence of poverty. The risks that these rural households face are the cause of this difference between poverty and vulnerability to poverty.

The stability of poverty status is a guarantee of the success of poverty alleviation policies. We have estimated the impact of access to credit on this stability. Our results 
show that access to credit increases the gap between poverty and vulnerability to poverty, thus making the poverty status of the household more unstable. Thus, we reject the hypothesis that households with access to credit have a more stable poverty status than those without access. In addition, some variables, such as the level of education of the householder, his sector of activity, his age have a significant effect on the stability of the poverty status of rural households in Côte d'Ivoire.

Regarding the spatial distribution of poverty in rural areas in Côte d'Ivoire, we noted that almost all of the administrative districts in our sample (33 in total) recorded a decrease or increase of more than 5 percent between the incidence of poverty and the vulnerability to poverty ratio. Only the Béré region recorded perfect stability between poverty and vulnerability to poverty. Thus, to the question of whether there is a concordance between the spatial distribution of poverty and vulnerability to poverty within rural areas in Côte d'Ivoire, we answer in the negative. For our part, we cannot speak, in view of our results, of correspondence of the spatial distributions of these two quantities in the rural environment in Côte d'Ivoire.

\section{References}

Bah, A. (2015) Estimating Vulnerability to Poverty using Panel data: Evidence from Indonesia. HAL archives-ouvertes, Available at: https://halshs.archivesouvertes.fr/halshs-00936199v3

Bidou J.E. et Droy I. (2012) Peut-on mesurer la vulnérabilité sociale et économique des ménages et des individus. 21p. Colloque International GEMDEV - UNESCO : La Mesure du Développement: Atelier 6: Vulnérabilité et Pauvreté, Paris (FRA), 2012/02/01-03

Chaudhuri, S., Jalan, J. and Suryahadi, A. (2002): “Assessing household vulnerability to poverty from cross-sectional data: A methodology and estimates from Indonesia", Department of Economics Columbia University. Available at: http://digitalcommons.libraries.columbia.edu/econ dp/117.

Institut national de la statistique (INS) (2015) «Enquête sur les Niveaux de Vie des Ménages en Côte d'Ivoire, ENV2015 »

Ouoya, Z. M. (2019), Business Sector, Level of Education and Access to Credit : What Influences on Vulnerability to Rural Households Poverty in Côte d'Ivoire. Studies and Scientific Researches. Economics Edition, No 30, pp 45-64, available at http://sceco.ub.ro/index.php/SCECO/article/view/441

Wisner B., Blaikie P., Cannon T., Davis I., 1994, 2003, At risk. Natural hazards, people's vulnerability and disasters, Routledge, London, $472 \mathrm{p}$. 